\title{
Sólo hay un bien: el conocimiento. Sólo hay un mal: la ignorancia Sócrates
}

\author{
There is only one good and that is knowledge. \\ There is only one evil and that is ignorance \\ Socrates
}

Rodolfo Ortiz Soto*

${ }^{\star}$ Ex presidente FEMECOT.

Siempre es el momento preciso, y hoy en día es necesario saber qué ha brindado la investigación a la ortopedia. Vivimos un mundo globalizado donde cada momento hay nuevos y diferentes puntos de vista, resultados y conclusiones.

El acuñamiento de la palabra Ortopedia en el siglo XVIII, utilizada por Andry en 1743 en su trabajo Ortopedia o el arte de prevenir y corregir en los niños las deformidades del cuerpo, se considera dentro de las primeras referencias de investigación en ortopedia.

La evidencia de investigación médica en México se remonta a 1772, con la edición de la primera revista en América, Mercurio Volante, y en 1864 la creación de la Academia Nacional de Medicina presente en forma ininterrumpida a través de su revista Gaceta Médica de México.

Aunque desde el siglo XIX la ortopedia y traumatología se consideran ciencia, la estadística de la literatura mundial sitúa a los países de América Latina con $1 \%$ de productividad. Nuestro país con $0.43 \%$ del PIB dedicado a la ciencia e investigación es un aporte escaso; un dato preocupante es que los recursos económicos otorgados a instituciones oficiales ha disminuido; además de los pocos recursos, se agregan otras razones que explican la baja productividad de literatura en América Latina, por ejemplo, tener que publicar en idioma inglés. Hay pocos cirujanos con soporte económico y medios adecuados para producir trabajos de calidad, se topan con la falta de apoyo de profesionales en la ciencia, investigación y publicación y con la dificultad de tener acceso a un adecuado órgano de publicación.

Es de gran importancia el hecho de que organizaciones académicas como la Federación Mexicana de Ortopedia y Traumatología A.C. (FEMECOT) se preocupen por llevar a sus agremiados, de una manera simple pero sólida, información necesaria que ayude al cirujano ortopedista a tener herramientas y a fomentar estrategias efectivas que puedan aplicar en su trabajo diario. El trabajo y esfuerzo en materia académica de la FEMECOT se vieron reflejados en la creación de su órgano de difusión, la Revista Orthotips, que desde hace 12 años en forma ininterrumpida ha sido publicada, llevando información a sus agremiados.

Es el momento de enfatizar el esfuerzo de los comités científico y editorial de la Federación Mexicana de Ortopedia y Traumatología A.C. (FEMECOT) en hacer la propuesta de proporcionar y facilitar todos los medios necesarios para incentivar la productividad de literatura de calidad, y como se menciona al principio, debe ser el momento preciso y conveniente para la comunidad médica científica de unirnos al reto de poner en práctica las propuestas de una administración visionaria, pujante y ambiciosa a través de su seleccionado comité científico de profesionales, y lograr así los objetivos de educar, facilitar e incentivar la publicación. 
Es de vital importancia contar con la asesoría adecuada, con profesionales que tengan el conocimiento del manejo de las herramientas, que se proporcione orientación, conducción y metodología, que se establezca una estrategia para lograr los objetivos de generar conocimientos nuevos, y que se nos motive a adquirir la necesidad de publicar, acción que cada vez cobra mayor relevancia en todas las entidades que ejercen la educación médica.

De esta manera, debemos sentirnos comprometidos, todo el gremio médico asociado, encabezado por sus comités, consejeros, coordinadores, encar- gados de servicios de instituciones y residentes, a producir artículos originales, desde revisión hasta reportes de casos.

De antemano merece una felicitación la FEMECOT que, a través de los comités científico y editorial, hace el esfuerzo de realizar un proyecto muy importante para la institución, con el fin de convertirlo en un medio de identidad.

Finalmente, la meta será incentivar la exposición de experiencias y enriquecer la producción y publicación de artículos de calidad que serán publicados por el órgano oficial de la federación, la Revista Orthotips. 